\title{
D Identidad y fantasma: situando \las nuevas prácticas de libertad del movimiento indígena en La Pampa
}

Axel Lazzari ${ }^{1}$

Para Pali y Julia

\section{Introducción}

En este artículo ${ }^{2}$ abordo aspectos del actual movimiento indígena -Rankülche en La Pampa que ponen en evidencia el vínculo entre las identidades étnicas construidas al interior de dispositivos de podersaber y las posibilidades de autonomización de sujetos subalternos. A lo largo de los últimos veinte años, la mayoría de las reemergencias aborígenes en la Argentina han construido sus reclamos destacando situaciones de postración cultural, pérdida territorial y disminución demográfica. Los adalides de estas reemergencias se las han arreglado para demostrar, dados los estándares hegemónicos de evidencia, la persistencia de la identidad aborigen a través del tiempo. Tal el caso, por ejemplo, de grupos como el Mapuche, el wichí o el toba (cf. Carrasco y Briones, 1996). En contraste, el resurgimiento del pueblo Rankülche en la provincia de La Pampa plantea dudas en cuanto a la continuidad de lo indígena en la identidad reclamada por los integrantes de este movimiento (Clifford 1988, Oliveira Filho 1998). No importa cuán activamente las políticas oficiales recientes y el activismo indígena hayan tratado de avalar el "retorno", los Rankülche no logran satisfacer plenamente los estándares oficiales de Indigenidad en la Argentina (vida comunitaria, territorialidad, residencia permanente y lenguaje vernáculo). Para muchos, ellos no parecen estar realmente

1 Candidato Doctoral en Antropología (Columbia University, EE.UU), Master en Antropología (Museu Nacional, UFRJ, Brasil), Licenciado en Ciencias Antropológicas (Universidad de Buenos Aires). Profesor de Antropología en la Universidad de Buenos Aires, Universidad Nacional de Córdoba y Universidad de San Martín. Investigador Formado del Instituto de Ciencias Antropológicas de la Universidad de Buenos Aires.

2 Aquí incluimos nuevas precisiones teóricas y empíricas al argumento presentado en Lazzari 2003. 
aquí y ahora. Están así atrapados entre un "pasado denso" y un "presente tenue", como si su reclamo de una identidad indígena no fuera lo suficientemente fuerte para socavar la idea generalizada de que tal identidad corresponde a un pasado tribal hoy extinguido ${ }^{3}$.

Sostengo en este escrito que el actual reconocimiento de los Rankülche reproduce, en el nuevo marco de una identidad provincial pluralista, patrones de (in)visibilización análogos a los que en el pasado determinaron el desvanecimiento de esta identidad $y$, por ende, del grupo indígena. Esta (in)visibilización también alcanza a las propias estrategias de identidad de los Rankülche pero, sin embargo, éstas señalan prácticas intersticiales de libertad que intentan reapropiar con fines diferentes los modos oficiales del reconocimiento pluralista. Estos problemas son investigados a través de un recorte que me permite identificar un dispositivo de Desvanecimiento del Ranquel, que se inicia a fines del siglo XIX, y un dispositivo de Retorno del Rankülche que aparece recientemente en los años noventa ${ }^{4}$. El objetivo general es doble. Por una parte, detectar los "fantasmas" que ayer minaban la inscripción del Ranquel como identidad aborigen en proceso de desaparición y que hoy socavan la representación del Rankülche como identidad que retorna. Por la otra, se trata de identificar cómo dichas fallas representacionales en los dispositivos de saber-poder anuncian el espacio donde hoy se desenvuelven prácticas de libertad que hacen al proyecto de autonomía cultural y política de los indígenas en La Pampa.

Uso la expresión analítica "fantasma" para referirme a las huellas que denuncian fracturas y lagunas en las estrategias de construcción de identidad. Si toda identidad presupone un cierre incompleto del

3 El pueblo que se autodefine como Rankülche se distribuye por toda La Pampa en ciudades, pueblos, caseríos y puestos rurales. La mayoría de los hombres que viven en la ciudad son trabajadores temporarios, con baja calificación y la mayor parte de las mujeres se desempeñan en el servicio doméstico. Otros están empleados en el sector público como administrativos, policías y maestros. En las áreas rurales, los Rankülche son generalmente peones y pequeños propietarios. Los Rankülche están políticamente organizados en cerca de veinte asociaciones y comunidades indígenas.

4 Siguiendo ciertos usos del lenguaje local, me apropio de los términos "Ranquel" y "Rankülche" para señalar, respectivamente, dos fórmulas de identidad aborigen: una presencia ida pero no del todo y una ausencia no totalmente suspendida. Por "Ranquel" refiero a aquellos indios que poblaron cerca de las fronteras ganaderas coloniales y republicanas por más de un siglo, que fueron sometidos a fines del siglo XIX, y que por último se convirtieron en sobrevivientes. El término "Rankülche" connota la nueva situación caracterizada por la presencia del movimiento indígena y las políticas de reconocimiento pluralista. 
exceso de significación (o de afectividad social), entonces puede ser deconstruida comenzando por los rastros que esta falla dejó en su superficie. Marilyn Ivy describe la lógica del fantasma o de la huella como un

"movimiento de algo que está muriendo, algo que se ha ido pero no del todo, suspendido entre presencia y ausencia, ubicado en un punto en que está y no está aquí, en el proceso repetitivo del ausentarse" (Ivy 1995:20; mi traducción).

Al hablar de "prácticas de libertad" retomo la discusión de Michel Foucault acerca de las emancipaciones posibles. Foucault concibe la libertad como una práctica efectiva de reconstitución de la identidad en el marco de un "dispositivo" que opera en un único plano inmanente de determinación. "Emanciparse" implica una práctica reflexiva acerca de los juegos de poder/verdad y sus trampas, siendo la principal de estas trampas la idea de que se puede arribar a un "fuera del juego" completamente irreversible y exterior al dispositivo de dominio. En la práctica de la libertad uno escapa "de un dominio de la verdad no jugando un juego totalmente diferente del juego de verdad, sino jugando el mismo juego de manera diferente o jugando otro juego, otra mano, con otras cartas" (Foucault 1996: 444). La reconstitución de la identidad indígena -de las posibles identidades que albergan lo Rankülche- implica para los actores las asunción práctica del mazo de diferencias/identidades étnicas en La Pampa. Frente a ello se abre la posibilidad de "jugarlas de otro modo" desarrollando otras identidades que pueden, aunque no necesariamente, dar sentido y fomentar nuevas autonomías. Justamente esta posibilidad de volver a dar las cartas viene dada por el propio devenir histórico, devenir que no es otra cosa que la lógica del fantasma que corroe tarde o temprano cualquier sedimentación "objetiva" y "natural". En este trabajo analizo dos de estos sedimentos en tanto que dispositivos que se nos presentan como conjuntos de sujetos, identidades, espacios y formas de dominio "dados" ${ }^{\text {. }}$ Planteo que el dispositivo de Desvanecimiento

5 En una entrevista, Foucault presenta al dispositivo como un "no concepto" que busca captar un conjunto heterogéneo de hechos, descriptos por él mismo como "discursos, instituciones, formas arquitectónicas, decisiones regulativas, leyes, medidas administrativas, enunciados científicos, filosóficos y morales, así como propuestas filantrópicas. En resumen, tanto lo dicho como lo no dicho". La segunda intención de la noción sería identificar los tipos de conexión dentro de este conjunto heterogéneo. Así, la idea permitiría pensar tanto la posibilidad de dispersión del conjunto (dada su heterogeneidad) como el principio histórico (en el sentido de 
engloba al del Retorno indígena, esto es, el espacio actual de visibilización de identidades indígenas se recorta contra el horizonte pasado de invisibilizaciones indígenas, creando un efecto paradójico de (in)visibilidad 6 mediante el cual la ocultación de lo indígena se realiza en su espectacularización. En base a esto, distingo metas diferentes en el análisis de cada dispositivo. El examen del Desvanecimiento del Ranquel se orienta a destacar las estrategias fallidas en la construcción de la identidad "pampeana" -territoriana y luego provincial- cuando ésta se ve confrontada a la necesidad de borrar lo indígena, liberando los "fantasmas" que como "restos Ranqueles" la aquejan. Dentro de esta lógica, enfoco el discurso de la Araucanización, el censo de 1895 de La Pampa Central y la articulación de la cuestión indígena con el mestizaje provincial. A su vez, abordo el dispositivo del Retorno del Rankülche desde la perspectiva del activismo indígena y de la política cultural de la provincia, recorriendo diversas tácticas de construcción de la identidad Rankülche para buscar allí las formas en que "el mismo juego" de la (in)visibilización de los Ranqueles se manifiesta en proyectos diferentes según sean activistas Ranqueles o las políticas oficiales quienes lo juegan. Aquí recurro como datos a un documento político Rankülche y al Ilamado "Monumento de los Indios Ranqueles" recientemente construido por el gobierno provincial.

\section{El Desvanecimiento del Ranquel}

\section{La Araucanización de las/los Pampas}

Si aceptamos lo que expresan las fuentes coloniales y republicanas, el desvanecimiento del Ranquel viene prefigurado muy profundamente desde el pasado aborigen. La identificación de quién es quién en las Pampas entre los siglos XVI y XIX siempre ha demandado ingentes esfuerzos por parte de testigos presenciales (oficiales militares, misioneros, refugiados y exploradores) y de los propios investigadores

dado efectivamente) que lo "ata" internamente pero de un modo contingente. Finalmente, una tercera dimensión del uso permite identificar la función estratégica que ahí se pone en juego. Un dispositivo es una respuesta a una "necesidad urgente", un arreglo de fuerzas dirigidas a la satisfacción de ciertos fines. Ver discusión en Lazzari 2005b.

6 Utilizamos este grafismo a los fines de marcar el carácter ambiguo de la visibilización como de la invisibilización. Asimismo es un recurso económico. 
(historiadores, etnólogos) puestos a interpretar a los primeros. Las estrategias para ubicar la silueta Ranquel en espacio y tiempo entre las varias entidades indígenas documentadas necesariamente conllevan ecuaciones, analogías y procedimientos de asimilación entre datos heterogéneos. Entre estas estrategias destaca la narrativa de la "Araucanización de las/los Pampas" como aquella que con el tiempo logró imponerse como marco de referencia gracias a un factualismo impregnado de necesidades geopolíticas. En efecto, la Araucanización permitió reescribir el "mapa étnico" de las Pampas, en un momento en que los gobiernos del Río de la Plata necesitaban identificar los contornos y la moralidad de los enemigos y posibles aliados para justificar las campañas militares ${ }^{7}$. Creer en la Araucanización presupone, aún hoy, extender un segundo manto de inmoralidad sobre la ya sospechosa identidad indígena evidenciado por las atribuciones de extranjería y agresividad. Los discursos legos e intelectuales producidos durante los siglos XVIII y XIX en la zona del Plata solían considerar que los pueblos araucanos habrían viajado a través de los Andes desde lo que hoy es Chile y se establecieron en los valles al este de la montaña y más tarde en las planicies pampeanas. Este proceso habría tenido lugar entre fines del siglo XVII y la década de 1840. Las diferentes oleadas de araucanos habrían entrado en cooperación y competencia con tribus Pampas, y de estas relaciones se habrían formado nuevas entidades

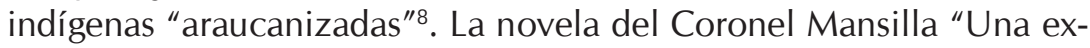
cursión a los indios Ranqueles" confirma lo que hacia 1870 parecía evidente:

"Los Ranqueles son aquellas tribus de indios araucanos [...] que migraron desde el oeste hacia el este de las laderas de los Andes [...] y han venido a establecerse entre los ríos Quinto y Colorado." (M ansilla 1967:2).

7 La cuestión acerca de si la araucanización existió "en realidad" es una cuestión que está presa de los presupuestos ontológicos y políticos de la ideología de la araucanización como régimen de verdad. Una pregunta alternativa podría formularse así: ¿Qué existió "en realidad"? Para una exploración de esta respuesta recomendamos consultar Boccara (1998 2001). Allí se argumenta a favor de que lo que existió no tenía contornos claros en función de la estructuración de una "lógica mestiza" a evadir al poder centralizante europeo e indígena. Aunque con reservas -pienso que esta lógica no era tan estructurante-el argumento de Boccara se asemeja a mi idea de fantasma.

8 Entendemos los etnónimos "Indios Pampas" y "Araucanos" como denominaciones coloniales con valor performativo que permiten reducir la complejidad étnica. Ver, por ejemplo, la discusión sobre las fuentes en Cooper 1946 y Canals Frau 1946. 
Las teo rías de la Araucanización consideraron a los indios Pampas como los habitantes originarios de las planicies "penetradas" por los araucanos después de abandonar su hogar en la Araucanía. A partir de las guerras de la independencia nacional, los araucanos empezaron a ser vistos como Indios Chilenos mientras los Pampas devenían Indios Argentinos ${ }^{9}$. A la agresividad se sumaba entonces la extranjerización en términos nacionales -más imperativos que los coloniales- ubicando a los "araucanos" y a los grupos "araucanizados" en una posición moral negativa. El desarrollo de la etnología en la Argentina durante el siglo XX prolongó esta tendencia agregándole el lenguaje científico de época y sus criterios de evidencia. Los etnólogos reformularon el proceso de Araucanización como la difusión de rasgos culturales araucanos en las culturas Pampa y Tehuelche, generalmente acompañada por la migración de contingentes araucanos (e.g. Canals Frau 1946). En este proceso se habrían producido aculturaciones selectivas entre los diversos grupos, siendo el "intercambio" más destacado por los estudiosos, la adopción del "complejo ecuestre" por parte de los araucanos y la difusión de la lengua araucana entre los indios Pampas. Los así Ilamados Pampas Araucanizados fueron concebidos como el efecto de este proceso. Su existencia suponía, en rigor, una tendencia degenerativa ya que para plasmarse, los araucanos habían "perdido" un bien "superior" como la agricultura y los Pampas habían "rendido" su lengua y su soberanía (Lazzari y Lenton 2000). Resumían la dudosa moralidad de los Pampas Araucanizados valoraciones como "pillaje", "bandidismo", "peligrosidad", "extranjeros" y otras similares que suelen atribuirse a las categorías de mestizos (aunque aquí se tratase de una mezcla entre indígenas $)^{10}$.

Asumiendo que esta narrativa funciona como verdad (factual) veamos cómo se relaciona con el Desvanecimiento del Ranquel. El discurso de Araucanización busca explicar la etnogénesis indígena como un proceso de sustitución y/o extinción de unas entidades socioculturales por otras, para lo cual debe presuponerse que dichas entidades -"tribus", "grupos étnicos", "pueblos", "razas"- existen, en sí mismas, de un modo más o menos estable y por lo tanto son delimitables. Aún

9 Recientes avances en antropología histórica y etnohistoria indígena exploran estos tópicos destacando las dialécticas de mutua constitución entre historias tribales y la construcción del estado colonial y republicano. Ver, por ejemplo, Bechis 1984; Boccara, op.cit.; Mandrini 1992; Lazzari 1996; Villar 2003.

10 De la Cadena 2000. 
más, este discurso genera su propio constructo -"pampas araucanizados" - el que, a su vez, es sustituido por el de "pampeanos/argentinos" en el marco de procesos violentos de nacionalización. En este sentido, la Araucanización es un reflejo ideológico invertido de un deseo de Argentinización pensada como des-indianización. Sean los Ranqueles, como sostiene Mansilla, araucanos, o no lo sean, como argumentan algunos activistas Ranqueles hoy, el punto es que no pueden evadirse de un discurso que los "araucaniza" (y argentiniza). Y esto significa que: a) su origen es problemático pues en el pasado remoto no hay Ranqueles puros sino "otra cosa": Pampas, Araucanos,...Mamülche (ver luego) y, b) su destino es inviable porque en el presente no hay Ranqueles plenos sino "otra cosa": pampeanos o argentinos. Así, pues la Araucanización genera un Ranquel que está siempre-ya en desvanecimiento. Más precisamente, atrapado entre la Araucanización y la Argentinización, su origen es tan borroso como su destino. Pero el discurso de la Araucanización falla allí donde tiene éxito pues al desrealizar y descentrar al Ranquel, activa en esta figura un mecanismo que la hace funcionar como rastro imborrable. El Ranquel inquieta las imágenes tranquilizantes de sustitución y síntesis de la Araucanización (y la Argentinización) al plantear con su mera presencia -lexical y "fáctica" (histórica y etnológica)- el límite a la disolución. Qué virtualidades identitarias y políticas contiene este modo de presencia es una pregunta que abordaremos en la segunda parte de este trabajo. Examinemos ahora otro avatar del dispositivo del Desvanecimiento del Ranquel.

\section{Una secuela estadística de la "Conquista del Desierto" en La Pampa}

La llamada Conquista del Desierto hacia fines de la década de 1870 completa la expansión territorial que comenzara en la época colonial. Entre 1878 y 1885, el ejército nacional vence la resistencia indígena destruyendo su sociedad como parte de la formación histórica de frontera. En 1884, las autoridades nacionales fundaron la Gobernación Nacional de La Pampa Central transformando en jurisdicción militar los antiguos territorios indígenas. La subsiguiente expansión de la propiedad privada, las colonias agrarias, los pueblos y los ferrocarriles crearon un nuevo conjunto de tensiones dentro de esta nueva en- 
tidad política que tenían por eje la desigual distribución de tierras (cf., por ejemplo, Asquini, Cazenave, Etchenique 1998). En este contexto, algunos de los jefes indios que habían colaborado con el ejército nacional en batallones de Indios Auxiliares recibieron algunas tierras en el norte y centro del nuevo territorio (Ranqueles) y en el sur (salineros y otros grupos). A esos contingentes se sumaron con el tiempo indios fugitivos y otras familias dispersadas conformando agrupamientos que estaban bajo un control más o menos laxo por parte de militares y misioneros. En estas circunstancias, la G obernación lanza un censo para establecer el estado de la población del territorio recién conquistado. Se manifiesta aquí una nueva faceta de la (in)visibilización de los indígenas, incluyendo en ellos a los Ranqueles.

\section{5: "Ya no quedan indios salvajes en el Territorio Nacional de La Pampa"}

Si es verdad que los momentos fundacionales de una identidad requieren de crímenes en los archivos de la memoria, entonces el Censo de 1895 de La Pampa Central es un ejemplo adecuado de tal proceder al declarar la ausencia de indios en el territorio ${ }^{11}$. En los tiempos posteriores a la conquista, las élites nacionales imaginaban una oleada de inmigración europea blanca que arrasara, con los vientos del "progreso", los últimos vestigios autóctonos en la Argentina. En su órbita, el gobierno de La Pampa cumplió con este propósito montando una fantasía estadística. D esde nuestra perspectiva, lo más destacable en este censo es la ausencia de la categoría censal "Indios" ${ }^{12}$. Los datos demográficos sobre nacionalidad o filiación racial/étnica se distribuyeron sólo entre las categorías excluyentes de "Argentino" y "Extranjero". Ahora bien, esto no habría sido problemático si los indios no hubiesen existido o nadie hubiese podido "verlos", pero, de hecho, alguien los "vio" a pesar de la ceguera ideológica recomendada frente a ellos. En efecto, Depetris descubre que, por lo menos, un censista registró en sus libretas veinte "indíjenas" [sic]. Sin embargo, este dato no constó en las cifras finales, y no se puede saber si estas veinte personas fueron

11 Bourdieu (1988), entre otros, ha tematizado la violencia performativa de los momentos de institución a partir de la autoridad del acto y del instrumento de representación como, en este caso, un censo.

12 Baso las interpretaciones de esta sección en el estudio de Depetris (1998). 
incluidas en la categoría "Argentinos" o simplemente descartadas. En cualquier caso, mi interés no radica, como el de Depetris, en determinar realmente cuántos indios habitaban La Pampa. Más bien, me propongo describir el funcionamiento del censo como un mecanismo para expulsar y a la vez documentar a los Indios como ausentes. En el siguiente comentario final del censo surge una pista sobre el proyecto de construcción de la nueva identidad territoriana a partir de la declaración de (in)visibilidad, que es también de incivilidad, de los indios:

"El resultado [del Censo] demuestra que en 1895 ya no quedan indios salvajes en el Territorio Nacional de La Pampa pues los remanentes de viejas tribus ya están sometidos y han sido contabilizados" [Publicación Oficial del Censo Territorial cit. en Depetris 1998: 139].

El criterio relevante para determinar el estado de civilización de los indios es precisamente estadístico: "tomarlos en cuenta" como "ex indios salvajes", es decir, "argentinos". Pero, ¿por qué razón no abrir una categoría censal para "indios colonizados" (los "indíjenas" del censista)? En primer lugar, esta estratagema de hacer desaparecer hay que interpretarla en el marco de la reticencia que el gobierno territoriano mostraba para aprobar la creación de colonias indígenas que gozaban de cierto apoyo del gobierno central. Al no registrar a lo que un censista "vio", el censo delata una estrategia explícita de ausentar. Pero una razón más básica parece radicar en que, si bien es posible trazar la diferencia entre "indio salvaje" e "indio sometido", ésta no es relevante frente a un discurso dominante que buscar hacer aparecer a todos los indios -salvajes o no- como "desaparecidos". Este hacer aparecer se muestra claramente en el hecho de que, a pesar de que lo indio no es visibilizado en una categoría "propia", surge en este comentario incidental como "remanentes de viejas tribus" que están contabilizados (como "argentinos"). En relación a esto último, podemos hablar de este censo como inserto un régimen asimilacionista de la diferencia que la esconde y margina, y distinguirlo de otros regímenes del pasado (coloniales, rosistas) y del presente (pluralismo étnico) que la muestran y la subordinan con distintos fines. En todo caso, este dar cuenta de los indios "sin contabilizarlos" como tales revela la ambigüedad del sujeto del discurso blanco que desea instaurar la ausencia del Indio y choca entonces con el peligro de ausentarse él mismo si no se provee, aunque sea al margen y a modo de fantasma, de un "rema- 
nente indio" donde apoyar y justificar su proyecto civilizatorio. En el vaivén entre un Indio que desaparece y aparece como "desaparecido", el Censo de 1895 es, ante todo, un documento del deseo del colonizador de producir indios como siluetas huecas. Es un arma de doble filo que sella un supuesto vacío al tiempo que señala su perímetro inestable y desestructurante. La mención de "indíjenas" y la advertencia final del censo que nos hablan de indios registrados pero no contados como tales, equivalen a reconocer el fracaso de los autoimpuestos deberes de civilización, dejando abierto el regreso amenazador de los indios, como "salvajes" o no, lo que es casi lo mismo ${ }^{13}$.

\section{Colonias (indígenas) e indigenismo criollizante}

La cuestión ya mencionada de la fundación de colonias es otro caso ejemplar de los estrechos márgenes por donde podía asomar lo indígena en el marco de un dispositivo post-conquista que los ignoraba o clamaba su desaparición. Veamos concretamente cómo se gestó la creación de la Colonia Emilio Mitre donde se asentaría un importante contingente de Ranqueles (alrededor de 700 personas). Se sabe que este grupo estaba integrado mayormente por sectores de la "tribu Cabral" que habían migrado a Fuerte Sarmiento antes de la campaña final del ejército e incluso habían prestado servicios en éste como "indios auxiliares" y "amigos". Ello les significó cierta compensación que se tradujo en su asentamiento post-conquista cerca de Victorica, en las fértiles tierras de La Blanca. Tras varios años en la zona, fueron "corridos" hacia 1897 reubicándose en la Travesía o Huevucu Mapu ("país del diablo"), tierras semiáridas situadas, por entonces, a dos o tres jornadas al O este de Victorica. Ante lo inevitable, los líderes del grupo "se hicieron ver" frente a las autoridades nacionales y pidieron, mostrando su foja de servicios en favor de la civilización, ayuda para instalarse en el desierto. Forzado a reconocer sus reclamos, el Poder

13 En 1966 cerca de 400 indios Ranqueles aparecieron por primera vez en el Censo Nacional de Indios aunque siendo sumados al total de la categoría "Araucanos" (Santander 1968). Dado que esta información se desprendía de una zonificación previa basada en criterios culturalistas, seguía quedando en las sombras la demografía Ranquel en el resto de la provincia. En 2001, el último Censo Nacional incluyó una pregunta sobre autoidentificación aborigen con el fin de evitar los peligros de la pre-asignación étnica (Urquía, Goldztein) pero su aplicación por parte de los censistas fue problemática. La invisibilización estadística se sigue escribiendo con otros medios. 
Ejecutivo Nacional fundó en 1899 la Colonia Pastoril Emilio Mitre, una extensión de tierras de 80.000 hectáreas. Desde el punto de vista oficial, la colonia se presenta como un expediente para asimilar a los "últimos remanentes de las viejas tribus" a través de la introducción de nuevas actividades productivas, formas de organización social y valores civilizados, destacándose el énfasis en lo agrícola, la sedentarización, la individualización y la educación. Este acto jurídico constituye, no obstante, otro mecanismo ambivalente de reconocimiento. Al considerarse la colonia como "pastoril" y no "indígena" (figura que estaba contemplada en la legislación) los Ranqueles, objeto de esa política de colonización, eran colocados en un doble vínculo de borramiento que se sostenía, por una parte, en la tipificación de los beneficiarios como "colonos" cuya aboriginalidad no era subrayada (en la cesión original se incluyen no indígenas) y, por la otra, en la entrega de tierras fuera de un régimen de reserva y a título individual y precario (permisionadas). Los rasgos de esta fundación demuestran la coherencia del dispositivo de desvanecimiento que, cuando "ve" a los indígenas produce performativamente un ente "en vías de desaparición", en este caso a través de la figura de un "colono" "permisionario" de tierras del fisco. La casi imposibilidad de escriturar (dados ciertos requisitos de productividad) inserta a los Ranqueles en una situación de semilegalidad hacia los personeros del Estado (inspectores) y de deuda hacia agentes privados (bolicheros), que lleva a dotar de "naturalidad" a aquello que es un mecanismo de desposesión fundiaria e invisibilización identitaria ${ }^{14}$. Cabe enfatizar que los orígenes de la colonia no pueden ser entendidos como un experimento planificado con antelación por indígenas que desean civilización y autoridades que la administran. Es más bien un proceso de tácticas improvisadas en una negociación entre el gobierno nacional, el territoriano y los propios caciques que resulta en una "colonia" que no es "indígena" pero, aún así, es el espacio posible de un proyecto de autocivilización por parte de los líderes indígenas. Este inevitable "jugar el juego" de otro modo, por parte los jefes

14 La creación de colonias agrarias en La Pampa debe ser examinada dentro del contexto más amplio de las políticas nacionales indigenistas y de tierra. La reubicación de indígenas en el sur y el norte de la Argentina entre 1895 y 1900 fue realizada de acuerdo con una casuística específica. El grado de civilización atribuido a los indios fue uno de los factores a la hora de determinar "quién, dónde y cómo" localizar. Así, mientras las misiones y las reducciones fueron los formatos preferidos de civilización para las "razas inferiores" de Tierra del Fuego y de el Chaco, las reservas y las colonias agrarias se expandieron entre los Mapuches y Ranqueles en La Pampa y el norte de la Patagonia. Ver Briones y Delrio (2002). 
Ranqueles, puede haber incidido en la elección del "desierto" como espacio distante, renovada "Tierra Adentro" donde fuese posible construir una autonomía de facto en base a un relativo aislamiento y una economía de autosubsistencia. Paradójicamente, ello se habría visto ayudado por cierta política de laissez passer de las autoridades justificada en su propia profecía de la extinción "natural" de los indios.

La cuestión de la colonia se liga al indigenismo cuya magia fundamental es hacer aparecer indios como seres pasibles de desaparición en un magma que los circunda. El nombre de ese magma es el "(estado) nación" y su dinámica moral es la del mestizaje, entendido en la Argentina moderna, como acriollamiento. El indigenismo clásico, que se extiende durante casi todo el siglo XX, postula el acriollamiento de los indígenas como vía de entrada en la nacionalidad. La identidad nacional argentina sólo toma en cuenta la inclusión de los indios si se someten a la promesa de des-indianizarse como "criollos". Así se explican los fracasos de las tentativas de redescribir la argentinidad en términos "indianistas" (cf., por ejemplo, el incidente de la "monarquía incaica" en los tiempos de la independencia, la prédica "euríndica" de Rojas y el "quichuismo santiagueño" en los orígenes del ERP) y el rol marginal que el indigenismo, como política social, jugó en las agendas gubernamentales (Lenton 1998) ${ }^{15}$. Exploremos en el siguiente ejemplo el modo en que se prolonga el desvanecimiento en el indigenismo pampeano al momento en que las "colonias (indígenas)" resurgen como problema hacia los años treinta.

\section{9: "El problema aún persiste pero la solución Ilegará en un futuro cercano"}

Examino aquí dos de las conferencias radiales sobre el "Pasado y presente de La Pampa" emitidas por Enrique Stieben, autor pampeano, docente y funcionario de la Secretaría de Educación de La Pampa ${ }^{16}$. La primera conferencia, bajo el título de "La conquista de las 15000

15 Esta breve exposición de la ideología criollizante que sostiene al indigenismo oficial no agota las profundas cuestiones teóricas y políticas acerca del mestizaje en América Latina. Para una discusión del tema ver De la Cadena 2000, entre otros.

16 Estas conferencias fueron transmitidas por Radio del Estado y patrocinadas por el diario pampeano La Capital. Su oficialización como discurso del gobierno quedó en evidencia al ser publicadas en 1939 como un capítulo de la Memoria del Gobierno del Territorio Nacional de La Pampa (La Pampa, 1939). 
leguas", vuelve a descubrir lo indígena como un "problema" que "aún persiste".

"En este momento los descendientes [de los indios fugitivos y sometidos] viven en pueblos y en colonias indígenas [...] pero van desapareciendo, debilitados por el alcohol, el tabaco y la miseria producida por su incapacidad técnica y su absoluta falta de cultura. Entendemos ahora por qué no fue suficiente ni aconsejable otorgar a las tribus tierras en posesión común. Tampoco habría sido útil otorgar escrituras a título individual sobre leguas y más leguas. Los indios padecían una completa falta de las nociones de orden, administración doméstica y trabajo. Durante siglos, fueron instruidos en el saqueo. La suya era una edad prehistórica; la guerra, era su ocupación. ¿Cómo se los podría haber transformado de la noche a la mañana en pastores pacíficos y honestos granjeros? [...] La fundación de colonias y escuelas habría sido una medida exitosa. El problema aún persiste pero la solución está en el futuro cercano". [Stieben 1939:18-19].

En "Problemas de La Pampa" el autor concibe un plan para acabar con el atraso de los indios:

"La única manera de volver útiles a sí mismos a quienes constituyen una carga social y un peligro es reunirlos en colonias adscriptas a escuelas técnicas dirigidas por artesanos, granjeros, maestros, etc. De tal modo no sólo borraremos la mancha de la ignorancia, cumpliremos un deber de humanidad, tomaremos medidas profilácticas y llevaremos alivio económico a la sociedad toda, sino que también daremos un ejemplo de fomento económico de los Indios para el resto de América". [Idem 36].

Hacia 1939, estaba claro para Stieben que las políticas indigenistas no habían satisfecho las expectativas oficiales de civilizar a los indios, confirmando de paso, la autonomía de facto de espacios indígenas. Los dispositivos de inscripción de ausencias indias como el Censo de 1895 y la Colonia Mitre no pudieron, debido a su intrínseca ambivalencia, evitar la reproducción de huellas indias allí donde buscaban borrarlas. A diferencia de las estrategias precedentes de Desvanecimiento, la de Stieben opera mediante el reconocimiento de un "problema indio" que equivale a algo peor que la incivilidad: una civilidad aparente que pone en riesgo a la sociedad toda. El peligro es doble y 
proviene de la persistencia de lo indio en las colonias y de la aparición de indios deficientemente civilizados que deambulan por los pueblos y ciudades. Lo indio parecía sobrevivir allí donde estaban demasiado juntos (se autoidentificaban) o demasiado sueltos (eran identificables por su apariencia). Para subsanar estos excesos, Stieben proponía una nueva colonización, racional esta vez, con mayor presencia estatal y orientada a una escolarización técnica. Reclamaba recanalizar el proceso de mestizaje criollizante en el cual los indios adquirirían tanto destrezas económicas como "cultura", moralidad e higiene. En la solución de este "problema" estaba en juego el "carácter" del aún naciente tipo pampeano. La "civilización pampeana" dependía de forjarse una imagen civilizada de sí misma para lo cual era preciso, entre otras cosas, borrar las manchas indígenas que aún la marcaban. No se trataba de una cuestión ideológica abstracta sino de una apuesta central en el proyecto de provincialización que, por entonces, era eje de un fuerte debate político al interior del Territorio ${ }^{17}$. El irredentismo pampeano reclamaba la construcción de una "nacionalidad provincial" con su fantasía étnico-racial (viejos criollos conquistadores y laboriosos gringos), su historia (la epopeya del desierto) y su propia literatura regional y folklore. La preocupación indigenista de Stieben encuentra aquí su sentido y puede interpretarse como un "estilo pampeano" de borrar indios. Mientras en el registro histórico presenta a los indios como condenados a la extinción en "La Pampa Criolla" y "La Pampa Grin-

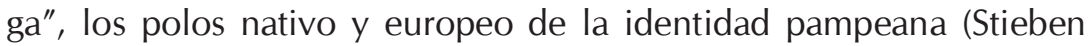
1946), su labor ficcional los recupera como una raza que vive entre fantasmas (Stieben 1951). Se da aquí una sugerente torsión. Apelando al consabido género "cuentos de fantasmas (indios)", el autor intenta compensar los fracasos del dispositivo de D esvanecimiento expulsando los residuos de la historia real hacia el mundo de la contemplación estética. Los "fantasmas de lo indio" -los indígenas aún no desaparecidos- se subliman como "indios fantasmas" y se reciclan así en el relato folklorizante de la pampeanidad. Stieben, el folklorista, se muestra, en sus cuentos de las "Pampas misteriosas", como un exorcista.

17 La Pampa obtuvo status de provincia en 1951 a pesar del hecho de que ya había cumplimentado los requisitos federales ya en 1912. Para la así llamada "gesta de la provincialización", ver Orizaola Roldán 1933-1934, entre otros. 


\section{El Retorno del Rankülche}

Llegados a este punto de nuestro recorrido, debemos preguntarnos por los inicios del actual presente del reconocimiento del Retorno de los Rankülche. ¿Cuáles son algunas de las tendencias que acompañan y habilitan este deseo del retorno? Desde la década de 1990, el imaginario de nacionalidad se ha venido flexibilizando, haciendo lugar a identidades y experiencias antes "ocultadas" ${ }^{18}$. Pero, en rigor, ello no pone en duda el ideal hegemónico del mestizaje criollizante; apenas extiende el intervalo espacial-temporal en que es dable a la "nueva" identidad/sujeto manifestarse frente al blanco. Este suele ser el modo socialmente efectivo en que quedan traducidas las elaboraciones normativas acerca del pluralismo, el multiculturalismo, la diversidad cultural o la interculturalidad. La Reforma Constitucional de 1994 se destaca como un documento de este nuevo estado de cosas en lo atinente al tema indígena. Allí se reconoce, por primera vez, un tipo especial de ciudadanía en la condición de "pueblos indígenas argentinos". Los miembros de estos pueblos gozan de "derechos especiales" colectivos en la medida en que pueda demostrarse la "preexistencia étnica y cultural" del grupo de referencia al momento (variable) de la conquista y colonización. Este nuevo espíritu queda reflejado en una especie de manifiesto político Rankülche.

\section{8: La Nación Mamülche, la Colonia Mitre como Hogar y el Pueblo Indígena}

En "Un Largo Camino de Regreso a Casa", el más conspicuo actor del movimiento indígena local, toma la palabra tras un largo y "estratégico silencio" de parte de los indios, decidido a confrontar la retórica de la no representación y la representación selectiva arraigada en el dispositivo del Desvanecimiento del Ranquel. Respecto de nuestro argumento, hay tres puntos en el escrito que son relevantes: la concep-

18 Estos cambios pueden ligarse a una nueva tendencia estructural en el modo de formación el estado nación. Esta rearticulación de las relaciones entre estado, sociedad, nación y ciudadanía recorta "crisis" diversas que muestran "nuevos" actores, imaginarios y regímenes de poder. En nuestro caso esto se manifiesta en el surgimiento del activismo indígena internacional, la producción legal sobre derechos humanos, políticos y culturales referidos a los pueblos indígenas, las políticas de "desarrollo sostenido" en territorios indígenas, el ecologismo internacional, entre otros factores (por ej. Stavenhagen 1995; Warren 1998; Escobar, 1999; Carrasco 2000). 
ción del pueblo Rankülche como Mamülche, el discurso de la Colonia Mitre como hogar, y la idea de Pueblo Indígena.

Canhué argumenta que el Rankülche es un pueblo distinto de los M apuche ${ }^{19}$. Tras compulsar las fuentes coloniales, afirma que en la zona pampeana, el término "Ranquel" aparece antes que "Mapuche" en boca de los "testigos oculares". De aquí salta a la conclusión de que los Ranqueles como entidad sociocultural, ya no como término, "estaban antes" que los Mapuche en la región. Desgraciadamente para la estrategia del autor, los archivos coloniales y nacionales que él consulta, también indican que los indios Ranqueles no pueden fácilmente desprenderse del atributo "araucanizados". Por esta razón, Canhué apuesta todo a su carta ganadora: la Nación Mamülche.

"Recién 1806, cuando el viajero chileno Don Luis de la Cruz recorrió nuestra tierra y describió lo que veía, oía y vivía, comienza nuestra historia. Antes de esa fecha, hay sólo hipótesis, ninguna de ellas seriamente documentada. Por eso, podemos decir de manera autorizada que antes de 1806 todo es prehistoria. Podemos asegurar, precisamente por el testimonio de de la Cruz, que los Mamülche eran los habitantes del Mamüll Mapu desde tiempos inmemoriales" [Canhué y col. 1998:1].

De acuerdo a esta interpretación, la auténtica etnogénesis del pueblo Rankülche debe remontarse a los Mamülche, habitantes del inmemorial y "prehistórico" Mamüll Mapu. Desde este punto de vista, la Araucanización de los Ranqueles deviene inmediatamente un fenómeno superficial. Pero la desmapuchización que defiende Canhué no está exenta de dobles lecturas. El signo "Mamülche" muestra que los Ranqueles pueden ser arrastrados a la "prehistoria", corriéndose el riesgo de transformarlos en fósiles vivientes. En un contexto político donde sobresalen las estrategias provincialistas de patrimonialización de lo indígena, éste, por cierto, no es un peligro menor. La interposición de la fecha "1806" impide que esto ocurra; abriendo un espacio liminar donde lo Rankülche nace de lo Mamülche como agente histórico. En la historia de Canhué, la subjetividad indígena toma su voz del síndrome Nación M amülche-Pueblo Rankülche, el intersticio des-

19 "Mapuche" es la presente (auto) identidad de los pueblos indígenas a los que me he estado refiriendo, siguiendo fuentes de archivo, como "Araucanos". Por lo menos, desde las movilizaciones políticas de la década de 1970, los activistas Mapuches han desechado este último término por considerarlo una categorización colonial y postcolonial. 
cubierto entre los Indios Pampas y Araucanos, y por lo tanto, ruptura táctica con la ontología esencialista de la Araucanizacion. La inmemorialidad junto con la historicidad atribuida a los Rankülche depende, no obstante, de un reconocimiento hacia la autoridad de los "ojos" y "oídos" del cronista colonial20.

Un impasse semejante se verifica en otra práctica de libertad de este autor que es agente social. Para Canhué, la lucha Rankülche por el reconocimiento es un viaje de vuelta al hogar. El texto identifica dos hogares, el "prehistórico", Mamüll Mapu, y el histórico, Colonia Mitre. Canhué monta una nueva narrativa para la colonia que desafía la de Stieben. Así, lo que en la historia oficial aparece como un vector de amnesia y amputación, si bien fallido, de lo indio, aquí se redefine como una estrategia intencional de supervivencia y resistencia aborigen. Cuando el desalojo de La Blanca en 1897, Ios Rankülche

"encomendaron a sus jefes Santos Catrenao Morales, Caleu Cabral y Curunao Cabral solicitar otras tierras, donde pudieran vivir pacíficamente. Eligieron la famosa y temible Travesía, donde ni siquiera los lagartos pueden vivir. El Presidente Roca pensó que había triunfado. Ahora anunciaría el fin de la guerra contra los primeros habitantes de La Pampa Central [...]. Los Indios no resistirían mucho en ese lugar; las familias se desintegrarían, abandonarían el lugar, y se pondría fin a la vida comunal, la lengua, la cultura, la filosofía y cosmología indígenas [...]. Pero un Indio con tierra no desaparece fácilmente. Aquellas 80.000 hectáreas, denominadas Colonia Indígena Emilio M itre, presenciaron el renacimiento de nuestro Pueblo, nuestra N ación, guiado por los líderes inteligentes que hicieron de este páramo un lugar floreciente. [...] Teníamos correo, telégrafo, escuela, juzgado de paz, caminos y hasta transporte público" [Idem 6] ${ }^{21}$.

20 El argumento Mamülche se conecta claramente con ciertos permisos otorgados por el culto provincialista al viaje de de la Cruz. Ver De la Cruz 1910; Cazenave 1998:83.

21 Desde las décadas de 1930-1940 la colonia fue perdiendo población Ranquel. Tras una serie de desastres climáticos y cambios en los patrones regionales de producción, los Rankülche comenzaron a emigrar a las ciudades vecinas y a Buenos Aires. Pero el problema principal fue la creciente pérdida de tierra a manos de pobladores no indios. Si bien este proceso ya se inicia en el origen de la colonia, se incrementó en los años sesenta con la mayor conexión del Oeste Pampeano al resto de la provincia. En 1972, tras un conflicto por la posesión de la tierra entre antiguos pobladores Rankülche y nuevos adjudicatarios, el gobierno provincial regularizó buena parte de la tenencia de la tierra. Sin embargo, la emigración continúa hasta hoy. Ver Canhué 2000 . 
En este texto la memoria de la autonomía post-conquista sirve a un discurso actual de autonomización. Rompiendo las expectativas progresistas de que la colonia fuese repudiada como un ghetto, se la recuerda como la ocasión de un renacimiento. Esto es compatible con la situación de autonomía de facto ya apuntada. Canhué llega a ver a los primeros jefes como héroes Rankülche ejerciendo libertades para introducirse en la civilización de acuerdo con sus propios términos, muchas veces más "literales" que los de los propios criollos y gringos. La Colonia como paradigma histórico de un renacer real y posible es el "hogar" al que se retorna y del que se parte hacia un proyecto de emancipación. A diferencia del prístino Mamüll Mapu, habitado eternamente por los "verdaderos indios", que son los Otros radicales, este hogar "colonial" alberga impurezas. Sus habitantes son "gringos" y "paisanos", y éstos últimos no son ni "indios" ni "criollos". El dispositivo de Retorno demanda purificarlos como "Rankülche", pero el autor, reconociendo oblicuamente que él mismo y su discurso son parte del efecto constitutivo del Desvanecimiento del Ranquel, mantiene la indefinición y la entrega a su público como un enigma constituyente.

El proceso de construcción de la Colonia Mitre como "hogar" no es indiscutible dentro de las filas del movimiento. Para aquellos cuyos ancestros, a diferencia de los de Canhué, no se remontan a las familias originarias de Colonia Mitre sino a individuos y familias esparcidos por otros sitios y ciudades -los "indios sueltos" que inquietaban a Stieben-, este hogar les resulta bastante artificial. De hecho, algunos sí lo consideran como un ghetto en el pasado y como un lugar condenado en el presente y apuestan, en cambio, a una utopía más "universal" y a la vez "individualista"22.

La idea del Rankülche como un pueblo indígena es presentada en el contexto de la reciente discusión acerca de la legitimidad actual de los tratados entre los Rankülche y los estados colonial y republicano (Briones y Carrasco 2000). La historia de "acuerdos pacíficos" realizados entre los siglos XVIII y XIX revela que:

"Nuestra Nación Mamülche fue violentamente anexada por el Estado Argentino. Lo hizo sin solicitar nuestro consentimiento libre e informado, sin respetar los tratados firmados ni la propia Consti-

22 Este hecho advierte sobre la necesidad de registrar diferentes memorias históricas dentro de un mismo grupo indígena pues éstas predisponen a construir utopías diversas con sus propias tácticas de autonomía. A veces, incluso, pueden poner en entredicho los propios valores "comunitaristas" del investigador. 
tución que demandaba 'acuerdos pacíficos con los Indios'. Lo mínimo que el Estado Argentino puede hacer ahora es reconocernos como 'Pueblos' preexistentes a la Nación Argentina". [Idem 9].

Canhué sostiene que el reconocimiento de la soberanía M amülche en los tratados del pasado establece un precedente jurídico y una obligación moral para que el Estado argentino reconozca a los Rankülche como un "Pueblo Indígena". El aspecto crítico de este sujeto jurídico, introducido por la Convención \# 169 de la O rganización Internacional del Trabajo (1989) y recuperado en la Constitución $\mathrm{N}$ acional, es el derecho de autodeterminación política (cf. Carrasco 2000). Del mismo modo que en el "nacimiento" de la historia Rankülche a los "ojos" de De la Cruz, el "derecho a la autodeterminación" del Rankülche depende de reconocer la autoridad del reconocedor. Si bien Argentina no es lo que se piensa -"es un Estado, no una Nación", desafía Canhué- hay un "estado" que debe reconocer a los indígenas sin presuponer "unidad espiritual". Para Canhué, las relaciones políticas entre los Rankülche y las autoridades argentinas no deben ser establecidas sobre el modelo de un "estado" acordando con "un sector de su población" (que equivale a una subunidad biopolítica de ese estado), sino sobre el modelo de las guerras diplomáticas de los siglos XVIII y XIX, donde "el concepto de frontera interna está bien definido". El reconocimiento de la soberanía indígena está entonces planteado en una situación de antagonismo y no de administración. No obstante, este antagonismo se da al "interior" -frontera interna- de un ámbito que compartido entre los oponentes. Esto me lleva a una observación final relacionada con la noción de "indio argentino". En dos textos de Canhué escritos en plena crisis del 2002 se muestra la fructífera ambigüedad de la noción de "frontera interna". En una carta dirigida al presidente Duhalde, Canhué promete, como líder del pueblo Rankülche, "ayudar al estado Argentino en caso de invasión o guerra internacional". En otro documento anticipa un plan de crisis que incluye el "cierre de nuestras fronteras a los países desarrollados [pues] Argentina es uno de los tres países del mundo que puede hacerlo" (Canhué firma como ciudadano argentino). En estos ejemplos queda claro que la demanda de autodeterminación como pueblo indígena no puede desligarse de versiones nacionales, e inclusive nacionalistas, del Estado argentino. Pero, bien visto, en la cosmología política de Canhué, el "Indio Argentino" no es sólo una señal de Desvanecimiento dentro de la Argentinidad sino el espacio de una práctica de la libertad en la "frontera interna". 
Las tácticas de Retorno desarrolladas en "Un Largo Camino de Regreso a Casa" expresan algunos de las paradojas que constituyen las subjetividades Rankülche contemporáneas. El nuevo campo de visibilidad construido en este texto tiende a interrumpir las tecnologías de Desvanecimiento sin siquiera satisfacer un completo retorno. La redescubierta Nación Mamülche desliza a los Rankülche hacia el Mamüll M apu y depende de la autorización colonial; Colonia M itre, recobrada como "hogar" de entre los anales de la dominación, es cuestionada por otros discursos Rankülche que la consideran una institución disciplinaria; y la categoría de Pueblo Indígena, depurada de la nacionalidad argentina, sólo parece ser usada como Indio Argentino. No obstante, todos estos dilemas no son emergencias mecánicas de contradicciones estructurales. Más bien, ejemplifican una tarea de apropiación reflexiva de las condiciones de dominación que puede, o no, conducir a un estratégico tipo de "ausencia", tanto más valioso en las circunstancias actuales de hipervisibilización:

“Decidimos volver. [...]. En marzo de 1983, el autor de estas líneas autoidentificado como "Indio" ante una audiencia que, en un primer momento curiosa y luego respetuosa, se preguntaba "¿Cómo es eso?" "¿No era que La Pampa no era más una provincia atrasada, una provincia sin indios?" En ese preciso momento, comenzó lo que Ilamamos un "Largo camino a casa". Mantuvimos un estratégico silencio durante cien años". [Canhué 2002] [3. $^{23}$.

Aquí, el "silencio" no se ve como impuesto por la historia de dominación, sino como una estrategia conciente de ocultamiento. Además, ¿quién está hablando realmente? ¿Es el "nosotros" colectivo? ¿O es el "Yo" del lonko partido entre el "autor" y el "Indio"? Considero estas líneas una prueba de la materialización de la libertad. Deben escribirse y publicarse. A través de la reapropiación del D esvanecimiento y un juego de distracciones estratégicas, el manifiesto contrarresta el poderoso corsé tanto del Desvanecimiento como del Retorno del indio real.

23 Este fragmento es una cita extraída de "Un Largo Camino de Regreso a Casa" tal como fue publicada en la WWW. 


\section{9: Monumento a los Indios Ranqueles}

El gobierno de La Pampa viene promoviendo una diferencia aborigen Rankülche dentro de un marco pluralista. ¿Hasta qué punto lo logra? ¿Acaso la idea del Rankülche como "indio provincial" no continúa el Desvanecimiento Ranquel? Analizo en esta sección el Monumento a los Ranqueles como un objeto arquitectónico que revela aspectos de la imagen del Indio que fomentan los organismos culturales provinciales; interpreto también la reacción paradigmática que despertó en la militancia indígena.

O chenta kilómetros al noroeste de Colonia M itre, se sitúa Leubucó, uno de los centros históricos de la sociedad Ranquel antes de su destrucción. Hasta hace poco un lugar en el "medio de la nada" (salvo por su condición de propiedad privada), estos terrenos se han convertido hoy en una especie de parque de la memoria donde construir sentidos y evocar presencias indígenas de acuerdo a un guión "reparador" (Curtoni, Lazzari, Lazzari 2003). Este "parque", vale destacar, se fue edificando de a poco, agregándose un monumento sobre otro, sin plan preconcebido y hasta con fines opuestos. El primer hito glorifica la "conquista del desierto" y el último -el mausoleo de Mariano Rosas- viene a mostrarse como un manifiesto Rankülche. En este sentido, el parque de la "memoria" logra su fin como mecanismo simbólico de reparación en tanto y en cuanto el visitante logra conectar conquista y reparación como una narrativa de progreso moral de los pampeanos. El "Monumento a los Indios Ranqueles" fue el segundo de los hitos edificados, en el año 1999. Constituyó, así, la primera intervención del estado provincial en el lugar con el fin de guiar el proceso de visibilización de los Rankülche, pero a diferencia de otras posteriores autodescriptas como "acompañamiento", este primer Monumento reveló de lleno el unilateralismo de la intención reparadora por parte de la provincia. El funcionario de la Subsecretaría de Cultura a cargo de su construcción comentó que el "Monumento de la Raza Ranquel" fue parte de un Plan de Patrimonio que buscaba "recuperar nuestra historia rastreando las huellas dejadas por nuestros ancestros, indios, criollos y descendientes de inmigrantes de ultramar". Las fuentes de este discurso tan redentorista como unívoco se remontan a la generación de intelectuales de la década de los sesenta y de los setenta que desafió construcciones de "pampeanidad" como la de Stieben. Al ampliar en extensión pero no en calidad la categoría de pueblo a los 
indígenas, este discurso se reveló como uno de los soportes ideológicos clave del "pluralismo real" en La Pampa tal como se expresa desde la década de 1990 (por ej. Morisoli 1987, Cazenave 1989, Asociación Pampeana de Escritores 1997, para una evaluación crítica cf. Maristany, D omínguez y García 1997).

¿Q ué tipo de estrategia de Retorno del Rankülche puede captarse en la volumetría concreta de este monumento? "Parece humano", de una humanidad "gigante" lograda a través de una estructura hueca de ocho metros de altura, laminada con placas de metal ocre. Su "cabe$z^{\prime \prime}$ es un cono invertido, el "brazo" derecho sostiene una lanza y un "tronco" rectangular se prolonga en dos "piernas" extremadamente largas que no tienen "pies". Detengámonos en las imágenes y símbolos que estas formas ponen en juego. En una primera aproximación, vemos una especie de "centinela ciego" de cara a la laguna. Al mismo tiempo, descubrimos que de su "pecho" o "corazón" brotan pequeñas figuras humanas que otean el paisaje circundante. Ellas representan a los ocho principales lonkos Rankülche. ¿Un "corazón humano" en un cuerpo humanoide? ¿U na esencia humana a descubrir tras la apariencia no humana? ¿"Gente" dentro de una "tribu irreconocible"? Aunque lo pequeño suele significar el "mundo de la proporción, el control y el equilibrio" y lo gigante la "violación de los límites y las reglas" (Stewart 1993:74), la combinación dialéctica de ambos que se nos presenta genera la sensación de lo Rankülche como algo desproporcionado. "Feo" suele ser la apreciación más general del monumento. Pero la "fealdad" -peligrosidad moral- de los gigantes, que suele poner en duda el bello orden establecido, tiene el efecto contrario cuando es exhibida en el espacio domesticado, el "parque". Los gigantes devienen así los más fieles guardianes de las instituciones, en este caso, las de un "pluralismo" que da al indio "su lugar" en el medio de la nada. Tal vez algo de eso capten los Rankülche al referirse al gigante con el apodo de "Robocop", un vigilante humanoide que controla que la identidad aborigen no desborde los estándares oficiales del Desvanecimiento. El monumento pretende ofrecer a la evocación una presencia histórica aborigen entendida como un "soberanía" que pertenece al "pasado". El acto de inauguración del monumento, ante autoridades de gobierno y militantes Rankülche, consistió precisamente en descubrir una tela que caía sobre el "pecho" de la estatua, revelándose entonces su "secreto a voces": los pequeños soberanos del pasado. Pero los des-cubrimientos, como sugiere Taussig (1999), son siempre 
incompletos y queda por saber, entonces, si puede haber "soberanía" Rankülche hoy. A propósito, un "jefe" indígena respondió a la prensa por el significado del monumento:

"Pensamos que es un tributo del Estado provincial al pueblo Rankülche; para nosotros encierra tres significados. Primero, el reconocimiento de nuestro pueblo; en segundo lugar, el establecimiento de una nueva relación entre el Estado provincial y los representantes de nuestro pueblo; y finalmente, el monumento en Leubucó es el primer paso hacia la restitución de los restos de Mariano Rosas"24 [La Arena, 10 de noviembre de 1999].

"Robocop" es un documento de las políticas culturales de La Pampa locales que van desde la recuperación del pasado indígena de La Pampa al reconocimiento político de los Rankülche. Pero también es la ocasión para una práctica de libertad aborigen dentro de las condiciones de un pluralismo "desde arriba". Esta praxis se expresa bajo la forma de un "agradecimiento crítico". El que habla dice que el monumento no representa "nuestro sentir" pero lo acepta como un "tributo" porque, bien o mal, reconoce el pasado Rankülche ${ }^{25}$. Es en este tipo de lógica indecidible que desorienta e incomoda a los reconocedores oficiales donde puede leerse la sustancia concreta de una autonomización.

\section{Conclusión: identidades, pluralismo convencional y autonomía como fantasma}

Por más de un siglo los Ranqueles se construyeron como la silueta hueca e imprecisa de otras identidades. Siluetas a las que se buscaba dar cuerpo. Estadísticas, discursos etnológicos e ingeniería social, por nombrar sólo unos modos de la actividad del dominio, los produjeron como invisibles en sus facetas de araucanos, argentinos, colonos y criollos. Traté de detectar las zonas donde estas estrategias

24 Para un abordaje de la restitución de los restos de Mariano Rosas, ver Lazzari 2005a, entre otros.

25 Sobre el carácter "humillante" y "venenoso" de los regalos, ver Mauss (1972), quien lo interpreta como el efecto de la disociación entre los aspectos social e individual de todo vínculo, con tendencia a resolverse socialmente, esto es, en el reconocimiento de unos con otros. Aquí mantengo abierta la posibilidad de que no haya tal resolución. 
de borrado habían fallado parcialmente y mostré la persistencia de fantasmas en el dispositivo de Desvanecimiento. Desde la década de 1990, el Desvanecimiento se metamorfosea, por partes, en Retorno. En un breve período, los aparatos culturales que solían mostrar como ausentes a los Ranqueles envejecieron, aunque sin morir, y ello se debe a la intervención de nuevos agentes históricos, entre ellos, el propio movimiento indígena. Este proceso ha abierto algunos espacios de libertad a aquéllos que reivindican que la Rankülche es una identidad aborigen contemporánea y no sólo una reliquia del pasado de la que se derivan derechos especiales. He examinado una de las tácticas Rankülche de autorepresentación en "Un Largo Camino de Regreso a Casa", Ilamando la atención sobre las maneras en que las nuevas entidades del Retorno tales como "Mamülche", Colonia Mitre como "hogar" y "Pueblo indígena" también están sometidas a la lógica del fantasma. En el registro de los organismos oficiales, el deseo del indio real ("puro") alimenta la estrategia de Retorno. La Subsecretaría de Cultura se acerca al reconocimiento de los Rankülche organizando espacios donde la "identidad cultural" se exhibe para una reparación histórica con propósitos didácticos y turísticos ${ }^{26}$. El "Monumento a los Indios Ranqueles" no está solo y se complementa con otras formas de reconocimiento tales como cursos de lengua aborigen ${ }^{27}$, exhibiciones de artesanía aborigen y talleres sobre historia indígena (cf., por ejemplo, Poduje 2001). Estas visibilizaciones, en tanto y en cuanto giran en torno a un presupuesto de pureza atribuido a lo indígena, generan dilemas e insatisfacciones y se transforman en un nuevo, aunque no intencional, mecanismo de desvanecimiento, ya no "dentro" de identidades otras como "criollo" sino "dentro" de un insondable "sí mismos" del que se guardan apenas imágenes estereotipadas. En otras palabras, la peligrosa ingenuidad de las estrategias oficiales estriba en creer que es posible un corte perfecto e irreversible entre un pasado de "olvido" del indio y un presente de "memoria", en el que ellas mismas se instalan autocomplaciéndose en los ideales del progreso, ahora en su forma "pluralista". Pero es éste un pluralismo administrativo

\footnotetext{
26 Vale la pena destacar que en otras agencias del estado provincial persiste con fuerza el dispositivo del Desvanecimiento del Ranquel. Tal es el caso de las esferas de las políticas de desarrollo social y humano cuyos diversos programas (vivienda, salud y planes de seguridad social) abordan a los Rankülche no como tales sino "pobladores" que no difieren en nada del resto. Ver Gobierno de la Provincia de La Pampa, 2000.

27 Para un análisis del proceso de revitalización lingüística, ver Lazzari 2006, entre otros.
} 
que tiende a afirmarse en una "celebración de la diversidad dentro de contextos de conflicto y acción colectiva pacificados" (Connoly 1995: xiii). Se trata de un ideal centrado en el control estatal que niega los procesos a través de los cuales las identidades se forjan, no por autogeneración espontánea, sino "a partir de viejas diferencias, heridas y esfuerzos" (Idem: xiv). El pluralismo convencional niega la pluralización de las identidades transformándolas y administrándolas, precisamente, como "identidades". Por eso es importante insistir y mostrar que toda identidad, aún más las de los subalternos, alberga elementos paradójicos que deben ser identificados no para socavarlas sino para tenerlos en cuenta en eventuales "nuevos principios" que deben ponerse en marcha cuando ya esa identidad ha sido colonizada. Es verdad que la transformación de los lenguajes monoculturales de la dominación estatal en lenguajes pluralistas ha producido espacios intersticiales de autoformación identitaria, pero, por lo mismo, ha suscitado nuevos estilos de apropiación hegemónica. Los activistas Rankülche lo saben mejor que nadie y algo de eso intenté mostrar a través de sus tácticas político-argumentativas. A diferencia de los "reconocedores", quienes instauran falsos cortes entre el pasado y el presente, creando así la ilusión de progreso y reparación, los que demandan reconocimiento saben, por su experiencia de sometimiento, que no hay un afuera y que toda autonomía supone una alteración, más o menos profunda, del "interior" del régimen de dominio. Saben que la autonomía posible se juega en moverse como "fantasmas" entre el dispositivo de Desvanecimiento del Ranquel y el dispositivo de Retorno Rankülche. Saben. ¿Pueden?

\section{Bibliografía}

ASQ UINI, Norberto, H. Walter CAZENAVE, Jorge ETCHENIQUE (1998) Conflictos sociales en la Pampa (1910-1921). Santa Rosa, La Pampa, Fondo Editorial Pampeano.

ASO CIACIO N PAM PEAN A DE ESCRITO RES (1997) Pampas del Sud.

Recopilación de textos que hacen a las raíces autóctonas de la provincia de La Pampa. Santa Rosa, La Pampa, Subsecretaría de Cultura. 
BECHIS, Martha (1984) Interethnic Relations during the Period of $\mathrm{N}$ ation-State Formation in Chile and Argentina. From Sovereign to Ethnic. Ann Arbor U niversity M icrofilms International.

BO CCARA, Guillaume (1998) Guerre et ethnogenèse mapuche dans le Chili colonial. L'invention du Soi. Paris, L'Harmattan.

BOCCARA, Guillaume (2001) "Mundos nuevos en las fronteras del Nuevo Mundo", en: Nuevo Mundo Mundos Nuevos 1.

BOURDIEU, Pierre (1988) "Espacio social y poder simbólico", en: Cosas Dichas. Buenos Aires, Gedisa.

BRIO NES, Claudia y Morita CARRASCO (2000) Pacta sunt Servanda. Capitulaciones, convenios y tratados con indígenas en Pampa y Patagonia (Argentina 1742-1878). Buenos Aires, VinciguerraIW GIA.

BRIONES, Claudia. "Mestizaje y Blanqueamiento como coordenadas de aboriginalidad y nación en Argentina", en: Runa XXIII. En prensa.

BRIONES, Claudia y Walter DELRIO (2002) “Patria sí, colonias también. Estrategias diferenciadas de radicación de indígenas en Pampa y Patagonia (1885-1900)", en: TERUEL, LACARRIEU y JEREZ, (eds.) Fronteras, ciudades y estados. Córdoba, Argentina. Alción Editora, pp. 45-78.

CANALS FRAU, Salvador (1946) "Expansion of the Araucanians in Argentina", en: J. STEWARD (ed.) Handbook of South American Indians. W ashington. Smithsonian Institution, Bureau of American Ethnology. Bulletin 143 (II), pp. 761-766.

CANHUE, Germán y col. (1998) Un Largo Camino de Regreso a Casa. La Pampa, Centro de la Argentina, Mimeo.

CAN HUE, Germán (2002) U n Largo Camino de Regreso a Casa.www. geocities.com/territoriosocial.

CARRASCO, Morita y Claudia BRIONES (1996) La tierra que nos quitaron: reclamos indígenas en Argentina. Buenos Aires, IG W IALhaka Honhat.

CARRASCO, M orita (2000) Los derechos de los pueblos indígenas en Argentina. Asociación de Comunidades Aborígenes Lhaka H onhat y Grupo Internacional de Trabajo en Asuntos Indígenas. Serie Documentos en Español \# 30. Buenos Aires, VinciGuerra. 
CAZENAVE, Héctor Walter (1989) "Espacio y Literatura". Seminario de Literatura Regional. Santa Rosa, La Pampa, U niversidad Nacional de La Pampa.

CAZENAVE, Héctor Walter [1981] (1998) "El Viaje de Luis de la Cruz. A 175 años de un viaje formidable y de una geografía insólita", en: DEPETRIS, J. C. y H. W. CAZEN AVE, Crónicas Ranquelinas. Santa Rosa, La Pampa, D epartamento de Investigaciones Culturales, Instituto Nacional de Asuntos Indígenas, pp. 82-84.

CLIFFORD, James (1988) "Identity in Mashpee", en: The Predicament of Culture. Twentieth-Century Ethnography, Literature and Art. Cambridge, Harvard U niversity Press, pp. 277-346.

CON N O LLY, W illiam (1995) The Ethos of Pluralization. London and Minneapolis, University of Minnesota Press.

COOPER, John (1946) "The Araucanians", en: STEWARD (ed.) $\mathrm{H}$ andbook of South American Indians. W ashington, Smithsonian Institution, Bureau of American Ethnology. Bulletin 143 (II), pp. 687-760.

CURTONI, Rafael, Axel LAZZARI y Marisa LAZZARI (2003) "Middle of Nowhere: a Place of War Memories, Commemoration, and Aboriginal Re-emergence (La Pampa, Argentina)", en: World Archaeology, Vol 35 (1), pp. 61-78.

DE LA CADENA, Marisol (2000) Indigenous M estizos. The Politics of Race and Culture in Cuzco, Perú, 1919-1991. Durham, N C, Duke University Press.

DE LA CRUZ, Luis [1806] (1910) "Descripción de la naturaleza de los terrenos y costumbres de los Peguenches", en: DE ANGELIS (ed.) Colección de O bras y Documentos relativos a la Historia del Río de la Plata. Vol. 1. Buenos Aires. Lajoune y Cia.

DEPETRIS, José Carlos (1998) "Los indígenas de la Pampa Central. Segundo Censo Nacional de Población de 1895", en: PODUJE (ed.) M emorias de las Jornadas Ranquelinas. Santa Rosa, La Pampa, Departamento de Investigaciones Culturales, Instituto $\mathrm{N}$ acional de Asuntos Indígenas, pp. 133-147.

DEPETRIS, José Carlos y Héctor Walter CAZENAVE (1998) Crónicas Ranquelinas. Santa Rosa, La Pampa, D epartamento de Investigaciones Culturales, Instituto Nacional de Asuntos Indígenas. 
ESCOBAR, Arturo (1999) El Final del Salvaje. Naturaleza, Cultura y Política en la Antropología Contemporánea. Santafé de Bogotá, CEREC.

FOUCAULT, Michel (1996) "The Ethics of the Concern for Self as a Practice of Freedom", en: Foucault Live: interviews (1961-1984). New York. Semiotext(e), pp. 432-449.

GOBIERNO DE LA PROVINCIA DE LA PAMPA (2000) La Pampa en Crecimiento. Santa Rosa, La Pampa. Secretaría de Gobierno. Santa Rosa, La Pampa, Subsecretaría de Promoción y Asistencia a la Comunidad.

IVY, M arilyn (1995) D iscourses of the Vanishing. M odernity, Phantasm, Japan. Chicago and London, The U niversity of Chicago Press.

LA ARENA. Edición 10 de noviembre de 1999. Santa Rosa, La Pampa.

LA PAM PA (1939) Memoria del Gobierno del Territorio Nacional de La Pampa. Santa Rosa.

LAZZARI, Axel (1996) ¡Vivan los indios argentinos! Análisis de las estrategias discursivas de etnicización/Nacionalización de los Ranqueles en situación de frontera, M. A. Thesis, Brasil, Museu Nacional/ U niversidade Federal do Rio de Janeiro.

- (2003) "Aboriginal Recognition, Freedom, and Phantoms: the Vanishing of the Ranquel and the Return of the Rankulche, La Pampa (Argentina)", en: Journal of Latin American Anthropology, 8 (3), pp. 59-83.

- - (2005a) "La repatriación de los restos de Mariano Rosas: disputas y paradojas en el reconocimiento multicultural de los Ranqueles". Conferencia pronunciada en Seminario Permanente de Antropología Social. Instituto de D esarrollo Económico y Social, Buenos Aires, Mayo. Mimeo.

- - (2005b) Dispositivo, Genealogía, Sujeto: ¿Foucault entre los ranqueles? Mimeo.

- (2006) "El Taller de Lengua y Cultura en el reconocimiento del Pueblo Rankülche: autonomía, deseo de lengua propia e indio fantasma". Ponencia presentada al VIII Congreso Argentino de Antropología Social, Salta, Setiembre, Mimeo. 
LAZZARI, Axel y Diana LENTON (2000) "Etnología y Nación: facetas del concepto de araucanización", en: Revista Avá 1 (1). Posadas, Universidad Nacional de Misiones, pp. 125-140.

LENTON, Diana (1998) "Transformaciones en el discurso gubernamental sobre el indígena: Argentina, 1930-1955". Informe Final Beca de Iniciación, Facultad de Filosofía y Letras (UBA). Mimeo.

MANDRINI, Raúl (1992) "Indios y Fronteras en el área pampeana (siglos XVI-XIX). Balance y Perspectivas", en: Anuario del IEHS, VII, pp. 59-73.

M AN SILLA, Lucio Victorio [1870] (1967) Una excursión a los indios ranqueles. Buenos Aires, Centro Editor de América Latina.

M ARISTANY, José, Carolina D O M IN GU EZ y Yanina GARCIA (1998) "Avatares de un paradigma invisible: del nacionalismo cultural al relato de la identidad 'regional'", en: Décimas Jornadas de Investigación. Santa Rosa, La Pampa, U niversidad Nacional de La Pampa, pp. 517-526.

MAUSS, Marcel (1972) [1925] "Ensayo sobre el Don", en: Sociología y Antropología. Barcelona, Barral.

MORISOLI, Edgar (1987) "Aproximación al concepto de región", en Seminario de Literatura Regional. Santa Rosa, La Pampa, Universidad Nacional de La Pampa.

OLIVEIRA, Joao Pacheco (1998) “¿Uma etnologia dos indios misturados? Situação colonial, territorialização e fluxos culturais", en: Mana, 4(1), pp. 47-77.

O RIZAO LA RO LD AN, Ismael (1933-1934) Historia del provincialismo de La Pampa. Buenos Aires, 2 Vols.

PODUJE, María Inés (comp.) (2001) Presencia Ranquelina. Santa Rosa: Gobierno de la Provincia de La Pampa, Ministerio de Cultura y Educación, Subsecretaría de Cultura. Departamento de Investigaciones Culturales.

SANTANDER, Josefa (1968) Contribución a la etnología pampeana. Separata del Tomo III del Censo Indígena Nacional. Buenos Aires. Ministerio del Interior.

STAVENHAGEN, Rodolfo (1995) "The rights and participation of indigenous peoples: a challenge for our times". Paper presented 
at the Workshop on Permanent Forum for Indigenous People, Copenhaguen, June 26-28.

STEW ART, Susan (1993) O n Longing. Narratives of the M iniature, the Gigantic, the Souvenir, the Collection. Durham and London, Duke University Press.

STIEBEN, Enrique (1939) El Pasado y el Presente de La Pampa. Cinco conferencias radiales. Santa Rosa, La Pampa, Gobierno del Territorio N acional de la Pampa Central. Suplemento de la M emoria Gubernativa.

STIEBEN, Enrique (1946) La Pampa. Su historia, su geografía, su realidad, su porvenir. Buenos Aires, Ediciones Peuser.

STIEBEN, Enrique (1951) Hualicho Mapu. Leyendas, cuentos y relatos de la Pampa misteriosa. Buenos Aires, Editorial Albatros.

TAU SSIG , M ichael (1999) D efacement. Public Secrecy and the Labour of the N egative. Stanford, California, Stanford U niversity Press.

URQUIA, Marcelo y Nicolás GOLDZTEIN. "Criterios censales para la medición de la población indígena en países de América y su relevancia para la medición de la población argentina en el censo 2000", en: SLAVSKY (ed.) Los Pueblos Indígenas en el Siglo XXI: Interculturalidad, Derecho, Justicia y Desarrollo. Buenos Aires, Instituto Nacional de Antropología y Pensamiento Latinoamericano. En prensa.

VILLAR, Daniel (ed.) (2003) Conflicto, poder y justicia en la frontera bonaerense. Bahía Blanca, Departamento de Humanidades de la U niversidad Nacional del Sur-Facultad de Ciencias Humanas de la U niversidad Nacional de La Pampa.

W ARREN, Kay (1998) Indigenous Movements and their Critics: PanMayan Activism in Guatemala. Princeton, Princeton University Press.

\section{Resumen}

En este artículo sostengo que el actual reconocimiento de los Rankülche reproduce, en el nuevo marco de una identidad provincial pluralista, patrones de (in)visibilización análogos a los que en el pasado determinaron el desvanecimiento de esta identidad $y$, por ende, grupo indígena. Esta (in)visibilización también alcanza a las propias estrategias de identidad de los Rankülche pero, sin embargo, éstas se- 
ñalan prácticas intersticiales de libertad que intentan reapropiar con fines diferentes los modos oficiales del reconocimiento pluralista. Estos problemas son investigados en el dispositivo de Desvanecimiento del Ranquel, que se inicia a fines del siglo XIX, y el dispositivo de Retorno del Rankülche que aparece en los años noventa. El objetivo general es doble. Por una parte, detectar los "fantasmas" que ayer minaban la inscripción del Ranquel como identidad aborigen en proceso de desaparición y que hoy socavan la representación del Rankülche como identidad que retorna. Por la otra, se trata de identificar cómo dichas fallas representacionales anuncian el espacio donde hoy se desenvuelven prácticas de libertad que hacen al proyecto de autonomía cultural y política de los indígenas en La Pampa.

Palabras claves: identidad, prácticas de libertad, régimen de pluralismo étnico, Ranquel/Rankülche.

Identity and phantom: locating the new practices of freedom of the indigenous movement in La Pampa

\section{Summary}

In this article, I maintain that the official recognition of Rankülche identity reproduces, in the new pluralist framework of provincial identity, patterns of (in)visibilization analogous to those that decreed the vanishing of this indigenous identity and group in the past. Such (in)visibilization is also identified in self-fashioned Rankülche strategies of identity, although they open up interstitial practices of freedom that endeavor to reappropriate official strategies of pluralist recognition. I investigate these problems in the dispositive of the Vanishing of the Ranquel, beginning in the 19th century, and the dispositive of the Return of the Rankülche started in the1990s. The aim is twofold. On one hand, to detect the "phantoms" that would undermine in the past the inscription of the Ranquel as an Indian identity and that today haunt the representation of the Rankülche as a returning identity. O n the other hand, I point to the ways in which those representational failures herald spaces where to develop practices of freedom that build up the cultural and political autonomy of the Indians in La Pampa.

Keywords: Identity, Practices of Freedom, Ethnic Pluralist Regime, Ranquel/Rankülche.

Recibido: 23/09/06, aceptado: 23/04/07. 
Axel Lazzari

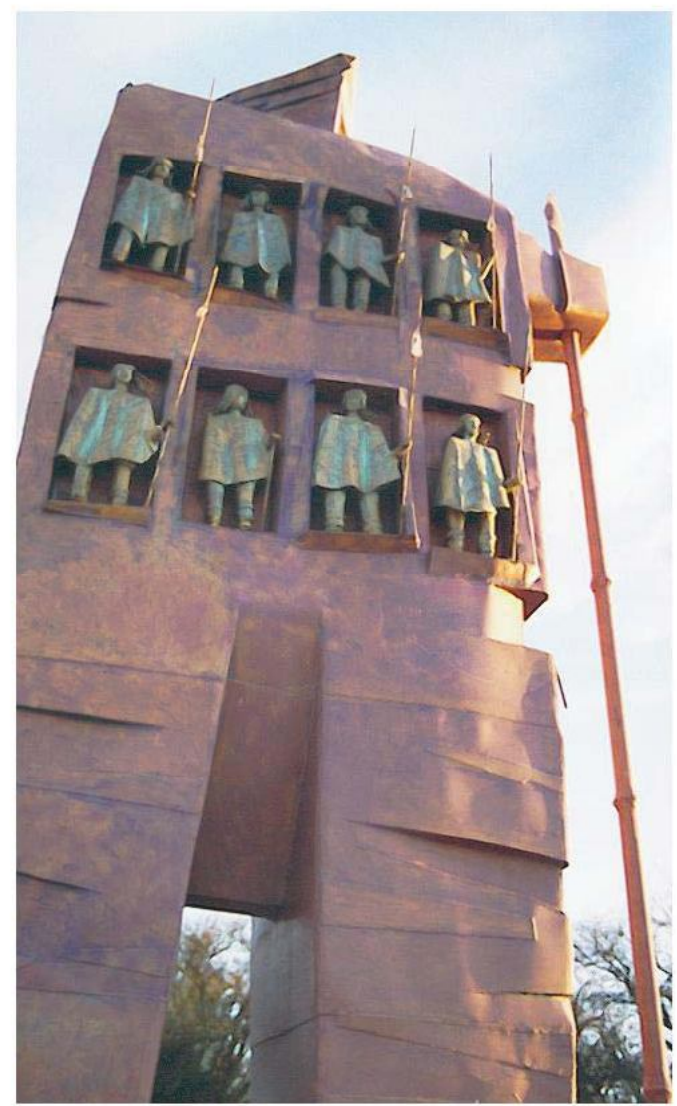

"Monumento a los Indios Ranqueles", Dto. Loventué, La Pampa. 